\title{
Cytotoxic 6-Alkylsalicylic Acids from the Endophytic Streptomyces laceyi
}

\author{
Nahyun Kim, Jin Chul Shin, Woncheol Kim, Bang Yeon Hwang, Beom Seok Kim, \\ Young-Soo Hong, Dongho Lee
}

Received: October 18, 2006 / Accepted: November 10, 2006

(C) Japan Antibiotics Research Association

\begin{abstract}
Two new 6-alkylsalicylic acids, salaceyins A and $\mathrm{B}$ were isolated by bioassay-guided fractionation from the culture of the endophytic Streptomyces laceyi MS53 and their structures were determined on the basis of spectroscopic data. Salaceyins A and B exhibited modest cytotoxicity against a human breast cancer cell line (SKBR3) with $\mathrm{IC}_{50}$ values of 3.0 and $5.5 \mu \mathrm{g} / \mathrm{ml}$, respectively.
\end{abstract}

Keywords alkysalicylic acid, Streptomyces, cytotoxic

\section{Introduction}

In our search for biologically active agents of natural origin, the culture broth of an endophytic actinomycete strain exhibited cytotoxic activity against a human breast cancer (SKBR3) cell line. Bioassay-guided fractionation of an EtOAc extract of a culture broth of Streptomyces laceyi MS53 resulted in the isolation of two new 6-alkylsalicylic acids (1 and 2, Fig. 1). Several 6-alkylsalicylic acid derivatives, biogenetically formed by the condensation of a fatty acid and three molecules of malonyl-CoA, have been isolated from plant sources including Anacardiaceae plants and Ginkgo biloba L., and exhibited antibacterial, antioxidant, insecticidal, and molluscidal activities [1 9]. We report herein the isolation and structural determination of two new 6-alkylsalicylic acids, together with cytotoxic

D. Lee (Corresponding author), N. Kim, B. S. Kim: Division of Biotechnology, College of Life Sciences and Biotechnology, Korea University, Seoul 136-713, Korea,

E-mail: dongholee@korea.ac.kr activities of the isolates against a human breast cancer cell line.

\section{Results and Discussion}

An endophytic Streptomyces strain (MS53) was isolated from a surface-sterilized stem of Ricinus communis L. Chemotaxonomic tests showed that the cell wall of the strain contained LL-diaminopimelic acid, indicating that it has cell-wall type I; no diagnostic sugars were detected in the hydrolysates of whole cells. Using partial $16 \mathrm{~S}$ ribosomal DNA sequence analysis, the strain was identified to be closely related to Streptomyces laceyi. The $16 \mathrm{~S}$ ribosomal DNA sequence identity was $99.38 \%$ (1460/ 1469 bp) [10 12].

Compound 1 was obtained as a colorless amorphous powder and was shown to possess a molecular formula of

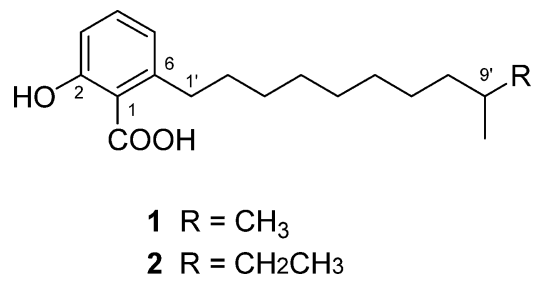

Fig. 1 Structures of salaceyins A (1) and B (2).

Y.-S. Hong (Corresponding author), J. C. Shin, W. Kim: Division of Molecular Therapeutics, KRIBB, Daejeon 305-806, Korea, E-mail: hongsoo@kribb.re.kr

B. Y. Hwang: College of Pharmacy, Chungbuk National University, Cheongju 361-763, Korea 
Table 1 NMR data for salaceyins A (1) and B (2) in $\mathrm{CDCl}_{3}{ }^{a}$

\begin{tabular}{|c|c|c|c|c|}
\hline & \multicolumn{2}{|c|}{$\delta_{\mathrm{C}}$} & \multicolumn{2}{|c|}{$\delta_{\mathrm{H}}$} \\
\hline & 1 & 2 & 1 & 2 \\
\hline 1 & 110.36 & 110.25 & & \\
\hline 2 & 163.63 & 163.67 & & \\
\hline 3 & 115.85 & 115.84 & $6.85 d(8.0)$ & $6.87 \mathrm{~d}(7.8)$ \\
\hline 4 & 135.40 & 135.35 & $7.34 \mathrm{t}(7.6,8.0)$ & 7.37 t (7.8) \\
\hline 5 & 122.75 & 122.69 & $6.75 d(7.6)$ & $6.77 \mathrm{~d}(7.2)$ \\
\hline 6 & 147.77 & 147.61 & & \\
\hline $\mathrm{COOH}$ & 175.64 & 175.74 & & \\
\hline $1^{\prime}$ & 36.48 & 36.51 & $2.96 \mathrm{t}(7.6)$ & 2.98 t (7.8) \\
\hline $2^{\prime}$ & 32.02 & 32.07 & $1.58 \mathrm{~m}$ & $1.61 \mathrm{~m}$ \\
\hline $3^{\prime}$ & $29.92^{b}$ & $29.49^{b}$ & $1.23 \sim 1.35^{b}$ & $1.23 \sim 1.39^{b}$ \\
\hline $4^{\prime}$ & $29.81^{b}$ & $29.49^{b}$ & $1.23 \sim 1.35^{b}$ & $1.23 \sim 1.39^{b}$ \\
\hline $5^{\prime}$ & $29.65^{b}$ & $29.67^{b}$ & $1.23 \sim 1.35^{b}$ & $1.23 \sim 1.39^{b}$ \\
\hline $6^{\prime}$ & $29.49^{b}$ & $29.83^{b}$ & $1.23 \sim 1.35^{b}$ & $1.23 \sim 1.39^{b}$ \\
\hline $7^{\prime}$ & 27.41 & 27.10 & $1.23 \sim 1.35^{b}$ & $1.23 \sim 1.39^{b}$ \\
\hline $8^{\prime}$ & 39.03 & 36.63 & $1.14 \mathrm{~m}$ & $1.23 \sim 1.39^{b}$ \\
\hline $9^{\prime}$ & 27.95 & 34.40 & 1.49 octet & $1.12 \mathrm{~m}$ \\
\hline $10^{\prime}$ & 22.64 & $30.01^{b}$ & $0.83 d(6.8)$ & $1.23 \sim 1.39$ \\
\hline $11^{\prime}$ & 22.64 & 11.40 & $0.83 d(6.8)$ & 0.86 overlap \\
\hline $12^{\prime}$ & - & 19.22 & - & 0.84 overlap \\
\hline $\mathrm{OH}$ & - & - & 10.98 br s & 11.01 brs \\
\hline
\end{tabular}

${ }^{a}$ TMS was used as the internal standard. Chemical shifts are shown in the $\delta$ scale with $J$ values $(\mathrm{Hz})$ in paraentheses.

${ }^{b}$ Interchangeable within the same column.

$\mathrm{C}_{18} \mathrm{H}_{28} \mathrm{O}_{3}$ by positive HRFABMS. The ${ }^{1} \mathrm{H}$ NMR spectrum of compound 1 displayed characteristic signals for an AMX spin system (1,2,3-trisubstituted benzene ring) at $\delta_{\mathrm{H}} 6.85$ $(1 \mathrm{H}$, doublet, $J=8.0 \mathrm{~Hz}, \mathrm{H}-3), 7.34(1 \mathrm{H}$, triplet, $J=7.6$ and $8.0 \mathrm{~Hz}, \mathrm{H}-4)$, and $6.75(1 \mathrm{H}$, doublet, $J=7.6 \mathrm{~Hz}, \mathrm{H}-5)$. In the aliphatic region, a benzylic methylene signal at $\delta_{\mathrm{H}} 2.96$ $\left(2 \mathrm{H}\right.$, triplet, $\left.J=7.6 \mathrm{~Hz}, \mathrm{H}-1^{\prime}\right)$, a homobenzylic methylene signal at $\delta_{\mathrm{H}} 1.58\left(2 \mathrm{H}\right.$, broad quintet like multiplet, $\left.\mathrm{H}-2^{\prime}\right)$, the signals coupled to each other at $\delta_{\mathrm{H}} 1.49(1 \mathrm{H}$, octet like multiplet, $\left.\mathrm{H}-9^{\prime}\right)$, and $0.83\left(6 \mathrm{H}\right.$, doublet, $\mathrm{H}-10^{\prime}$ and $\left.\mathrm{H}-11^{\prime}\right)$ as well as the overlapped signals $\left[\delta_{\mathrm{H}} 1.23 \sim 1.35(10 \mathrm{H}\right.$, multiplet, $\mathrm{H}-3^{\prime}, 4^{\prime}, 5^{\prime}, 6^{\prime}$, and $\left.7^{\prime}\right)$ and $1.14(2 \mathrm{H}$, multiplet, $\left.\mathrm{H}-8^{\prime}\right)$ ], suggested the presence of a 9-methyldecyl unit, which was substantiated by the ${ }^{13} \mathrm{C}$ NMR and mass spectra. The results obtained from the 1D and 2D NMR spectra indicated that compound $\mathbf{1}$ is a salicylic acid derivative with a 9-methyldecyl substitution in the molecule. The position of this alkyl group was determined unambiguously as $\mathrm{C}-6$ by salient HMBC correlations (H-5/C-1, C-1', H-1'/C-1, C-5, C-6). Therefore, the structure of the new compound, 1 was elucidated as 6-(9methyldecyl)salicylic acid.
The ${ }^{1} \mathrm{H}$ and ${ }^{13} \mathrm{C}$ NMR spectra of compound 2 were almost superimposable with those of $\mathbf{1}$, except for the branch moiety of the 9-methyldecyl group of the latter compound. The absence of the iso-type methyl branch signals (9-methyldecyl unit) and the presence of the upfield shift signal for the terminal methyl group at $\delta_{\mathrm{C}} 11.40$ (C-11') due to the $\gamma$-effect of the methyl substitution at C-9' indicated that compound $\mathbf{2}$ has an anteisotype methyl branched chain rather than an iso-type 9-methyldecyl unit as in $\mathbf{1}$ [13]. The stereochemistry of C-9' position was inferred to be $S$ based on the positive optical rotation of anteiso-type compounds [14]. Accordingly, the structure of the new compound, 2 was assigned as 6-(9 methylundecyl)salicylic acid and confirmed using HRFABMS and 2D NMR techniques.

Salaceyins A (1) and B (2) were evaluated against human breast cancer cell line (SKBR3) and both compounds exhibited modest cytotoxicity with $\mathrm{IC}_{50}$ values of 3.0 and $5.5 \mu \mathrm{g} / \mathrm{ml}$, respectively. Salicylic acids with alkyl side chains were previously reported to exhibit antibacterial and molluscidal activities [2 4]. More specifically, anacardic acids isolated from Anacardiaceae plants showed 
synergistic antibacterial effects against methicillin-resistant Staphylococcus aureus, which has troubled hospitals worldwide with persistent infections $[4,5,15,16]$. Therefore, it is obvious that more research is needed to investigate the antibacterial activity of $\mathbf{1}$ and $\mathbf{2}$.

\section{Experimental}

All melting points were determined on an Electrothermal 9100 instrument without correction. Optical rotation was measured on a JASCO P-1020 polarimeter. UV spectra were measured on a Shimadzu UV-1601 UV-visible spectrophotometer. NMR spectra were recorded on a Varian UNITY 400 spectrometer with $\mathrm{CDCl}_{3}$. ESI-MS and HRFABMS were obtained on Platform quadrupole and JMS-HX110A/HX110A Tandem Mass spectrometers, respectively. Preparative HPLC was carried out on a Varian system.

Determinations of the isomer of diaminopimelic acid and the whole-cell sugar pattern were carried out as described by Hasegawa et al. using colonies from agar plates (ISP2 medium) [11]. A 16S rRNA gene sequence of strain MS53 was amplified by PCR using universal bacterial $16 \mathrm{~S}$ rDNA primers (forward primer adapted from primer fD1 of Weisburg et al. [12]; reverse primer adapted from primer p1525r of Chun and Goodfellow [10]). The 16S rDNA was sequenced using a DNA automated sequencer (Applied Biosystems) and an Amersham Pharmacia Biotech Cy5 Thermo Sequenase dye terminator kit.

MS53 was cultured in a seed agar medium, ISP4. The fully grown mycelia or spore suspension was used to inoculate a $1000-\mathrm{ml}$ baffled flask containing $300-\mathrm{ml}$ of a seed medium consisting of yeast extract $0.3 \%$, Bactopeptone $0.5 \%$, malt extract $0.3 \%$, glucose $1.0 \%$, sucrose $10.3 \%$, and $\mathrm{MgCl}_{2} \cdot 6 \mathrm{H}_{2} \mathrm{O} 0.1 \%$, which is a modified YEME broth. The flasks were cultivated on a rotary shaker ( $170 \mathrm{rpm}$ ) for 3 days at $28^{\circ} \mathrm{C}$. For the production cultures, $300 \mathrm{ml}$ of the modified YEME medium in 1000-ml baffled flasks was inoculated with the seed culture, and the flasks were incubated at $28^{\circ} \mathrm{C}$ and $170 \mathrm{rpm}$ for 7 days. The cultured broth (8 liters) was extracted with EtOAc twice and these extracts were filtered through a fritted funnel in vacuo to remove insolubles. The volume of the filtrate was reduced in vacuo and then partitioned between EtOAc and $\mathrm{H}_{2} \mathrm{O}$ to give the organic extracts $(1.3 \mathrm{~g})$. Fractionation of the EtOAc extract was initiated by Silica gel chromatography using a $\mathrm{CHCl}_{3}-\mathrm{MeOH}$ gradient as mobile phase, and fractions obtained were pooled based on TLC analysis. Fraction 4, eluted with $\mathrm{CHCl}_{3}-\mathrm{MeOH}(15: 1)$, was passed through a Sephadex LH-20 column using
$\mathrm{CHCl}_{3}-\mathrm{MeOH}(1: 1)$ and further purified by HPLC [YMCPack Pro C18, $250 \times 20 \mathrm{~mm}$ i.d., $\mathrm{MeCN}-\mathrm{H}_{2} \mathrm{O}(0.05 \%$ TFA) gradient, $10 \mathrm{ml} /$ minute] to afford compound $\mathbf{1}(10.0 \mathrm{mg}$, $0.77 \% \mathrm{w} / \mathrm{w})$ and compound $2(2.0 \mathrm{mg}, 0.15 \% \mathrm{w} / \mathrm{w})$.

Salaceyin A (1). Colorless amorphous powder; UV $(\mathrm{MeOH}): \lambda_{\max }(\log \varepsilon) 244$ (3.72), $310 \mathrm{~nm}(3.51) ;{ }^{1} \mathrm{H}$ and ${ }^{13} \mathrm{C}$ NMR data, see Table 1; ESI-MS $m / z 291.4[\mathrm{M}-\mathrm{H}]^{-}, 583.7$ $[2 \mathrm{M}-\mathrm{H}]^{-}$; HRFABMS $\mathrm{m} / \mathrm{z}$ 293.2119, calculated for $\mathrm{C}_{18} \mathrm{H}_{29} \mathrm{O}_{3}, 293.2117$.

Salaceyin B (2). Colorless amorphous powder; $[\alpha]_{\mathrm{D}}^{24}$ +5.0 (c 0.1, $\mathrm{CHCl}_{3}$ ); UV (MeOH): $\lambda_{\max }(\log \varepsilon) 244$ (3.56), $310 \mathrm{~nm}(3.35) ;{ }^{1} \mathrm{H}$ and ${ }^{13} \mathrm{C}$ NMR data, see Table 1; ESI-MS $\mathrm{m} / \mathrm{z} 305.4[\mathrm{M}-\mathrm{H}]^{-}, 611.6[2 \mathrm{M}-\mathrm{H}]^{-}$; HRFABMS $\mathrm{m} / \mathrm{z}$ 307.2274, calculated for $\mathrm{C}_{19} \mathrm{H}_{31} \mathrm{O}_{3}, 307.2273$.

Compounds 1 and $\mathbf{2}$ were evaluated for cytotoxicity against human breast cancer (SKBR3) cell line according to established protocols (positive control, geldanamycin: $\mathrm{IC}_{50}$ value of $40 \mathrm{nM}$ ) [17].

Acknowledgements The work was supported by the 21C Frontier Microbial Genomics and Applications Center (MG05-0303-2-0 to Y.-S.H.), Ministry of Science and Technology, Republic of Korea and by the BioGreen21 Program (20050301034453 to B. S. Kim), Rural Development Administration, Republic of Korea. We thank the Korea Basic Science Institute for providing certain instruments used in this study.

References

1. Asakawa Y, Masuya T, Tori M, Campbell EO. Long chain alkyl phenols from the liverwort Schistochila appendiculata. Phytochemistry 26: 735-738 (1987)

2. Corthout J, Pieters L, Claeys M, Geerts S, Vandenberghe D, Vlietinck A. Antibacterial and molluscicidal phenolic acids from Spondias mombin. Planta Med 60: 460-463 (1994)

3. Kubo I, Nihei K-I, Tsujimoto K. Antibacterial action of anacardic acids against methicillin resistant Staphylococcus aureus (MRSA). J Agric Food Chem 51: 7624-7628 (2003)

4. Muroi H, Kubo I. Antibacterial activity of anacardic acid and totarol, alone and in combination with methicillin, against methicillin-resistant Staphylococcus aureus. J Appl Bacteriol 80: 387-394 (1996)

5. Muroi H, Nihei K-I, Tsujimoto K, Kubo I. Synergistic effects of anacardic acids and methicillin against methicillin resistant Staphylococcus aureus. Bioorg Med Chem 12: 583-587 (2004)

6. Cesla P, Blomberg L, Hamberg M, Jandera P. Characterization of anacardic acids by micellar electrokinetic chromatography and mass spectrometry. J Chromatogr A 1115: 253-259 (2006)

7. Hecker H, Johannisson R, Koch E, Siegers C-P. In vitro evaluation of the cytotoxic potential of alkylphenols from 
Ginkgo biloba L. Toxicology 177: 167-177 (2002)

8. Toyomizu M, Okamoto K, Ishibashi T, Chen Z, Nakatsu T. Uncoupling effect of anacardic acids from cashew nut shell oil on oxidative phosphorylation of rat liver mitochondria. Life Sci 66: 229-234 (2000)

9. Trevisan MTS, Pfundstein B, Haubner R, Wurtele G, Spiegelhalder B, Bartsch H, Owen RW. Characterization of alkyl phenols in cashew (Anacardium occidentale) products and assay of their antioxidant capacity. Food Chem Toxicol 44: 188-197 (2006)

10. Chun J, Goodfellow M. A phylogenetic analysis of the genus Nocardia with 16S rRNA gene sequences. Int J Syst Bacteriol 45: 240-245 (1995)

11. Hasegawa T, Takizawa M, Tanida S. A rapid analysis for chemical grouping of aerobic actinomycetes. J Gen Appl Microbiol. 29: 319-322 (1983)

12. Weisburg WG, Barns SM, Pelletier DA, Lane DJ. 16S ribosomal DNA amplification for phylogenetic study. J Bacteriol 173: 697-703 (1991)
13. Wang CY, Wang BG, Wiryowidagdo S, Wray V, van Soest R, Steube KG, Guan HS, Proksch P, Ebel R. Melophlins $\mathrm{C}-\mathrm{O}$, thirteen novel tetramic acids from the marine sponge Melophlus sarassinorum. J Nat Prod 66: 51-56 (2003)

14. Mills JA, Klyne W. The correlation of configuration. In Progress in Stereochemistry. Vol. 1, Ed., W. Klyne, p. 205, Butterworth Scientific Publications, London (1954)

15. Grundmann H, Aires-de-Sousa M, Boyce J, Tiemersma E. Emergence and resurgence of meticillin-resistant Staphylococcus aureus as a public-health threat. Lancet 368: 874-885 (2006)

16. Henderson DK. Managing methicillin-resistant Staphylococci: A paradigm for preventing nosocomial transmission of resistant organisms. Am J Med 119: S45-S52 (2006)

17. Buchanan GO, Regentin R, Piagentini M, Rascher A, McDaniel R, Galazzo JL, Licari PJ. Production of 8-demethylgeldanamycin and 4,5-epoxy-8-demethylgeldanamycin from a recombinant strain of Streptomyces hygroscopicus. J Nat Prod 68: 607-610 (2005) 